\title{
Electrodeposition of Paramagnetic Copper Film under Magnetic Field on Paramagnetic Aluminum Alloy Substrates
}

\author{
Bambang Soegijono, ${ }^{\mathrm{a},}{ }^{\dagger}$ Ferry Budhi Susetyo, ${ }^{\mathrm{a}, \mathrm{b}}$ Yusmaniar, ${ }^{\mathrm{c}}$ Musfirah Cahya Fajrah ${ }^{\mathrm{d}}$ \\ ${ }^{a}$ Department of Physics, Universitas Indonesia, Depok 16424, Indonesia \\ ${ }^{\mathrm{b}}$ Department of Mechanical Engineering, Universitas Negeri Jakarta, Jakarta 13220, Indonesia \\ ${ }^{c}$ Department of Chemistry, Universitas Negeri Jakarta, Jakarta 13220, Indonesia \\ ${ }^{d}$ Department of Physics, Institut Sains dan Teknologi Nasional, Jakarta 12640, Indonesia \\ †Corresponding author:naufal@ui.ac.id
}

Received: 10 July, 2020; Accepted: 14 September, 2020; Published: 1 October, 2020

Electrodeposition of paramagnetic copper $(\mathrm{Cu})$ from a sulfate solution was investigated under magnetic fields and two different current densities. Static magnetic fields have been used during electrodeposition of paramagnetic $\mathrm{Cu}$ onto paramagnetic aluminum $(\mathrm{Al})$ substrate to enhance the deposition rate and to alter crystallographic orientation and morphology of the film. The magnetic field might be attributed to the field-induced convection that disrupts the depletion layer near the electrode and that might also be correlated to $\mathrm{Cu}, \mathrm{Al}$, and oxygen dissolved in the solution as paramagnetic materials. An X-ray diffractometry, a scanning electron microscope with energy dispersive spectrometry, a potentiostat, and a digital camera were used for characterizing the crystal structure, morphology, the electrochemical behavior, and wettability, respectively. The results show that, at the current density of $10 \mathrm{~mA} \mathrm{~cm}$, raising the magnetic field from 800 to $1400 \mathrm{G}$ increases the cathode current efficiency and alters the electrochemical behavior, the crystal growth, and the
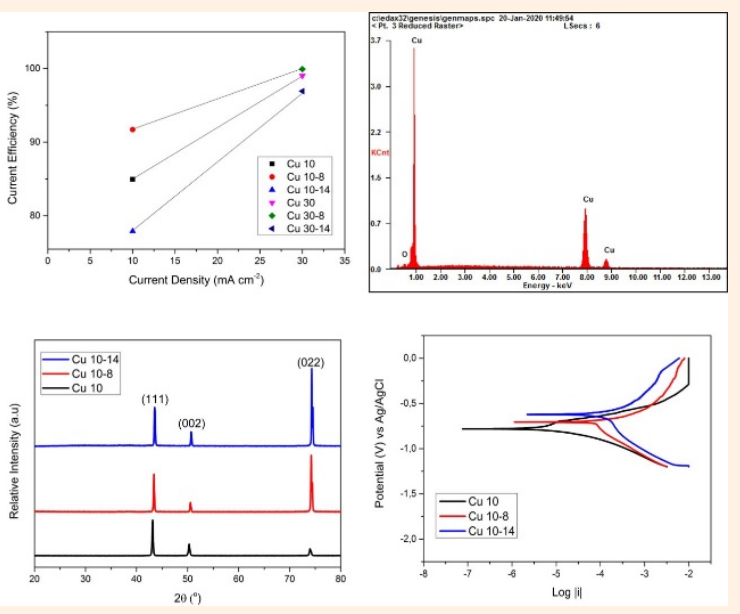
crystallite size. At the current density of $30 \mathrm{~mA} \mathrm{~cm}^{-2}$, the magnetic field alters the growth and crystallographic orientation. The static magnetic field exposed during electrodeposition of $\mathrm{Cu}$ onto the $\mathrm{Al}$ alloy can control the film properties, especially crystallographic orientation and the oxygen content.

Keywords Cu Films; Al alloy; Magnetic field; Paramagnetic

\section{INTRODUCTION}

In recent years, paramagnetic $\mathrm{Cu}$ has replaced $\mathrm{Al}$ as a metal for interconnects material for the microelectronics industry due to its high thermal and electrical conductivity compared with $\mathrm{Al}[1,2]$. $\mathrm{Cu}$ metal can be deposited by several methods, such as physical vapor deposition, chemical vapor deposition, electroless deposition, and electrodeposition [3]. Electrodeposition is an established production method for thin metal films and for surface finishing [4]. In the last few decades, the influence of magnetic fields on electrochemical deposition processes has been widely studied. Several studies have carried out to assess the effect of magnetic positions, such as perpendicular [5], parallel [6], and rotating [7] positions. Electrodeposition in the magnetic field produces different deposition rates [8], morphology [9], structures [10], corrosion currents [11], and corrosion potentials [12].

A previous research [13] has shown that various constant current plating produces difference corrosion potentials and X-ray diffraction (XRD) peak intensities of the crystal planes. A magnetic field imposed parallel to the substrate 
resulted in the shift of the corrosion potential to the negative value, whereas a field perpendicular to the substrate produced the corrosion potential shifting to the positive value [5]. Rotating magnets with various field strengths and spinning rates resulted in different morphology and XRD peak intensities [7]. A magnet placed behind the substrate resulted in larger grain sizes and lower plating thicknesses [14]. Furthermore, the magnetic field with different strengths produced different XRD peak intensities for (111), (002), and (022) crystal planes [15].

Electroplating under the static magnetic field is an exciting interdisciplinary (electrochemistry and magnetism) area. It is good opportunities for developing and producing nanostructure materials and for expanding the magnetic field's application in the industry. In some respects, magnetic effects are not yet well understood.

If the magnetic field is exerted during the electrodeposition process, several forces may exist [16]. The first magnetic field effect is the Lorenz force;

$$
\boldsymbol{F}_{\mathrm{L}}=\boldsymbol{J} \times \boldsymbol{B},
$$

where $\boldsymbol{B}$ is the applied magnetic field, $\boldsymbol{J}$ is the current density and $\boldsymbol{F}_{\mathrm{L}}$ is the Lorentz force per unit volume. This force acts on moving ions in the solution, resulting in the convection flow of the entire solution [17]. It has the maximum value when the magnetic field is perpendicular to the current density.

The second force is a paramagnetic force.

$$
\boldsymbol{F}_{\mathrm{p}}=\frac{\chi_{\mathrm{m}} B^{2} \boldsymbol{\nabla} C}{2 \mu_{\mathrm{o}}}
$$

Here, $\boldsymbol{F}_{\mathrm{p}}$ is the paramagnetic force, $\chi_{\mathrm{m}}$ is the molar susceptibility of the ions, $\mu_{0}$ is the permeability of free space, and $C$ is the concentration. A uniform magnetic field affects the susceptibility of magnetic ions, creating a local energy density. When $C$ has a gradient in different layer near the cathode, this leads to the paramagnetic force [18].

The third force is the electrokinetic magneto-hydrodynamic proposed by Olivier et al. [19];

$$
\boldsymbol{F}_{\mathrm{EK}}=\sigma_{\mathrm{d}} \boldsymbol{E}_{\|} / \delta,
$$

where $\sigma_{\mathrm{d}}$ is charge density of diffusion layer, $\delta$ is the thickness of the boundary layer, $\boldsymbol{E}_{\|}$is an induced nonelectrostatic field. This force acts only on the diffusion double layer near the cathode

The fourth possible force is a magnetic gradient force, which has been studied by Ragadale et al. [20] and Tanimoto et al. [21]. This force follows the equation;

$$
\boldsymbol{F}_{\nabla \boldsymbol{B}}=\chi_{\mathrm{m}} C B \boldsymbol{\nabla} \boldsymbol{B} / \mu_{0} .
$$

This force acts on paramagnetic and diamagnetic ions in different directions according to the gradient of the magnetic field.

The objective of the present research is to investigate effects of the magnetic field and the current density on electrodeposition of a nonmagnetic metal (paramagnetic) $\mathrm{Cu}$ on the $\mathrm{Al}$ (paramagnetic) alloy as a substrate. The magnetic fields might influence the deposition rate, the structure, morphology of the $\mathrm{Cu}$ electrodeposits, and the corrosion behavior. The static magnetic fields of 800 and $1400 \mathrm{G}$ perpendicular to the sample surface and current densities of 10 and $30 \mathrm{~mA} \mathrm{~cm}^{-2}$ were used during the electrodeposition process. Surface morphology, the structure, the corrosion behavior, and wettability were examined by scanning electron microscope (SEM) with energy dispersive spectrometry (EDS), XRD, linear sweep voltammetry (LSV), and a digitally camera, respectively.

\section{EXPERIMENTAL}

A direct current electrodeposition process of the $\mathrm{Cu}$ films was performed at room temperature on the $\mathrm{Al}$ alloy $(\mathrm{Fe} ; 1.63$ $\mathrm{wt} \%, \mathrm{Mg} ; 1.49 \mathrm{wt} \%$, and $\mathrm{Al}$; balance) substrate with a diameter $\varnothing 2.33 \mathrm{~cm}$. A virgin make-up solution (VMS) consisting of $0.25 \mathrm{~mol} \mathrm{~L}^{-1} \mathrm{CuSO}_{4} \cdot 5 \mathrm{H}_{2} \mathrm{O}$ was used for electrodeposition.

$\mathrm{Cu}$ films were electrodeposited under the galvanostatic control with a constant current density of $10 \mathrm{~mA} \mathrm{~cm}^{-2}$ and $30 \mathrm{~mA} \mathrm{~cm}^{-2}$. The constant magnetic fields of 800 and 1400 $\mathrm{G}$ and perpendicular to the surface of the samples were used for an experiment during the electrodeposition process (Figure 1).

Before electrodeposition, the substrates were mechanically polished with a sandpaper and cleaned in an ultrasonic cleaner with distilled water. The samples with the current density $10 \mathrm{~mA} \mathrm{~cm}^{-2}$ and the magnetic fields of 0,800 , and $1400 \mathrm{G}$ are designated as $\mathrm{Cu} 10, \mathrm{Cu} 10-8$, and $\mathrm{Cu} 10-14$, respectively. The samples $\mathrm{Cu} 30, \mathrm{Cu} 30-8$, and $\mathrm{Cu} 30-14$ are the ones with the current density of $30 \mathrm{~mA} \mathrm{~cm}{ }^{-2}$ and the magnetic fields of 0,800 , and $1400 \mathrm{G}$, respectively.

FE-SEMFEI INSPECT F50 energy dispersive analysis of X-rays (EDAX) EDS analyzer was used for the morphology observation. Rigaku RINT 2000 (CuK $\alpha$ radiation) was used to identify the crystal structure, and HighScore Plus software was used to refine the XRD pattern using a Rietveld refinement method. For the LSV investigation, Digi-Ivy DY 2311 with a three-electrode cell system (a

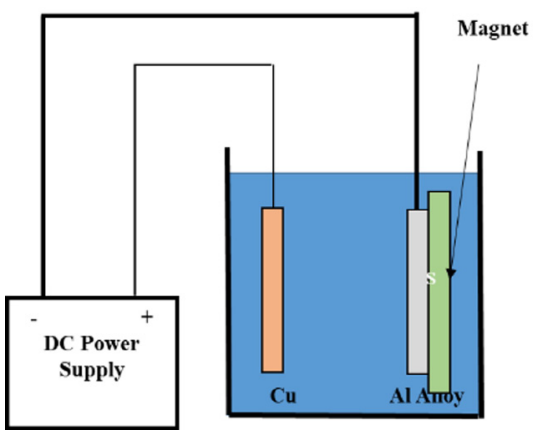

Figure 1: Schematic diagram of electrodeposition of $\mathrm{Cu}$ onto the Al alloy substrate with various current densities and magnetic fields. 
potentiostat), whose working, counter, and reference electrodes were $\mathrm{Al}$, a $\mathrm{Pt}$ wire, and $\mathrm{Ag} / \mathrm{AgCl}$, respectively, was used. The LSV investigation was conducted with a scan rate of $10 \mathrm{mV} \mathrm{s}^{-1}$ in $3.5 \% \mathrm{NaCl}$. The water contact angles were taken using a digital camera.

\section{RESULTS AND DISCUSSION}

\section{A. Cathode current efficiency and deposition rate}

In the electroplating process, the oxidation process $(\mathrm{Cu}$ $\rightarrow \mathrm{Cu}^{2+}+2 \mathrm{e}^{-}$) occurs at the anode, and a reduction process $\left(\mathrm{Cu}^{2+}+2 \mathrm{e}^{-} \rightarrow \mathrm{Cu}\right)$ occurs at the cathode. A material to be coated is, thus, placed at the cathode. When the current is applied, the $\mathrm{Cu}^{2+}$ ions are depleted in the surroundings of the cathode. This makes a diffusion layer around the cathode. A hydrogen evolution is a secondary possible reaction at the cathode during electrodeposition from aqueous solutions. It can be neglected in many cases. Hydrogen is absorbed as $\mathrm{H}$ atoms, not $\mathrm{H}_{2}$ molecules, but the $\mathrm{H}$ atoms may also form molecular $\mathrm{H}_{2}$, which is trapped in voids or vacancies to induce hydrogen embrittlement [22]. The current efficiency of copper deposition is less than $100 \%$ since some portion of the current is used to discharge hydrogen ions from water [23].

The current efficiency and the deposition rate are important properties for industrial plating. The current efficiency of electrodeposition is a ratio between the mass of the deposited $\mathrm{Cu}$ film and the mass of $\mathrm{Cu}$ calculated according to the Faraday's law below:

$$
m=\frac{Q M}{n F}=\frac{i t M}{n F}
$$

Here, $m$ is a mass of $\mathrm{Cu}$ deposits, $Q$ is electric charge, $i$ is current, $t$ is time, $F$ is termed the Faraday constant, $M$ is a molar mass of the $\mathrm{Cu}$ species, and $n$ is a number of electrons involved in the reaction and equals 2 in the present case.

Current efficiency curves of electrodeposited $\mathrm{Cu}$ onto the

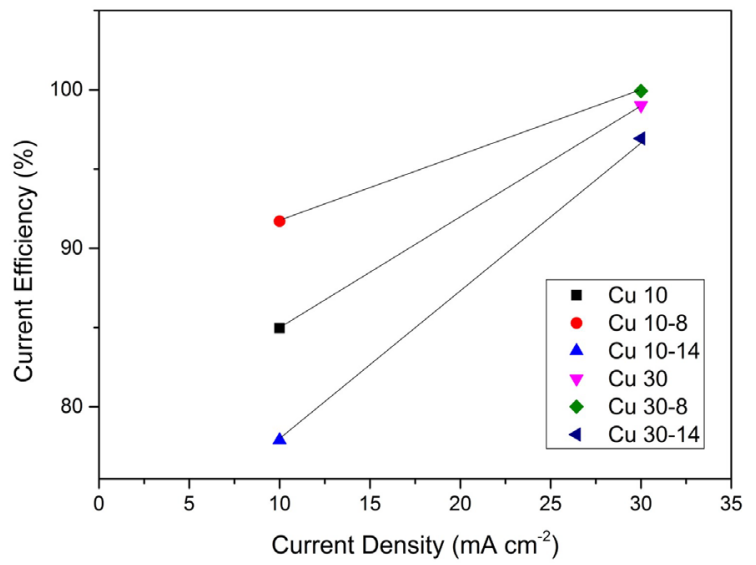

Figure 2: Cathode current efficiency of electrodeposited $\mathrm{Cu}$ onto the $\mathrm{Al}$ alloy substrate with various current densities and magnetic fields.
Al alloy substrates are presented in Figure 2. The current efficiency is affected by the current density and the magnetic field. At the low current density $\left(10 \mathrm{~mA} \mathrm{~cm}^{-2}\right)$, the magnetic field affects the current efficiency more than at the high current density $\left(30 \mathrm{~mA} \mathrm{~cm}{ }^{-2}\right.$ ). This is probably due to the magnetic attraction of the paramagnetic $\mathrm{Cu}^{2+}$ ion in the solution. Increasing the magnetic field would cause $\mathrm{Cu}^{2+}$ to move faster and, hence, the current efficiency increases. The higher current density causes a higher evolution of the hydrogen gas at the stronger magnetic field. The secondary reaction of hydrogen evolution during electrodeposition occurs at the cathode, which could disturb the cathode current efficiency. This is the reason why the current efficiency for $\mathrm{Cu} 10-8$ is higher than that for $\mathrm{Cu} 10-14$. It also happens to the samples $\mathrm{Cu} 30-8$ and $\mathrm{Cu} 30-14$ [24].

The deposition rate is the amount of deposited copper divided by the time required to deposit. Deposition rate curves of electrodeposited $\mathrm{Cu}$ onto the $\mathrm{Al}$ alloy substrates are presented in Figure 3. The deposition rate increases as the current density increases [25]. Park et al. found that, by rising the magnetic field from 0 to $600 \mathrm{G}$, there was a significant increase in the deposition rate [15]. The deposition rate of the sample with the current density of $30 \mathrm{~mA}$ $\mathrm{cm}^{-2}$ is higher by approximately $25 \mu \mathrm{m} \mathrm{h}^{-1}$ than the sample with $10 \mathrm{~mA} \mathrm{~cm}^{-2}$. The effect of the magnetic field on the deposition rate is similar to the effect of the magnetic field on the current efficiency. The $\mathrm{Cu} 10-8$ sample has the highest deposition rate among three other samples. The deposition rate of $\mathrm{Cu} 30-8$ is higher than that of $\mathrm{Cu} 30-14$.

\section{B. Scanning electron microscope (SEM)}

SEM images of electrodeposited $\mathrm{Cu}$ onto the $\mathrm{Al}$ alloy substrates are presented in Figure 4. By raising the magnetic field, the grain of the $\mathrm{Cu}$ films become smaller [26, 27]. Figure 4(a,d) shows different morphology due to different current densities $\left(10\right.$ and $\left.30 \mathrm{~mA} \mathrm{~cm}^{-2}\right)$ in the absence of a magnetic field. Figure $4(a-c)$ shows an influence of the magnetic field $(0,800$, and $1400 \mathrm{G})$ with a constant current

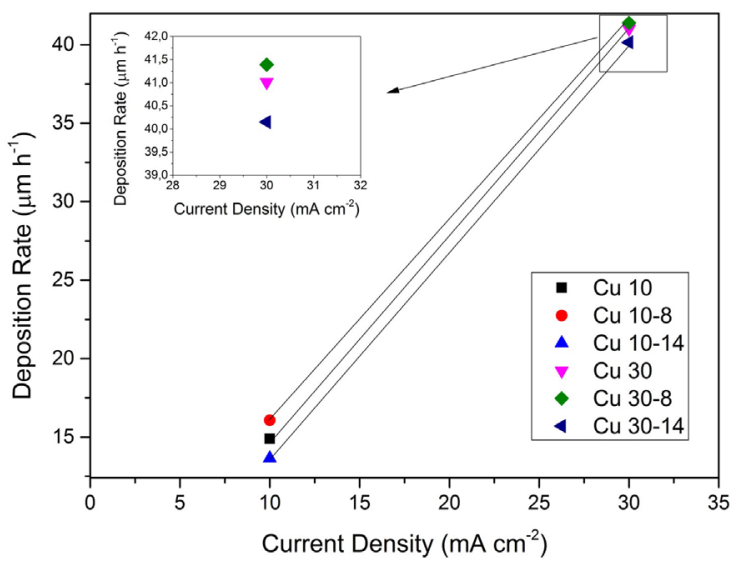

Figure 3: Deposition rate of electrodeposited $\mathrm{Cu}$ onto the $\mathrm{Al}$ alloy substrate with various current densities and magnetic fields. 
density $\left(10 \mathrm{~mA} \mathrm{~cm}^{-2}\right)$ on morphology of the samples. $\mathrm{Cu} 10$ shows a dendrite-like structure [Figure 4(a)], but a similar structure is not seen in other samples. It seems that the magnetic field may inhibit the dendrite formation. It is seen that the current density and the magnetic field affect surface morphology of the $\mathrm{Cu}$ film. Surface morphology is classified into three groups based on the over-potential dependence on the electrolyte composition. These are a faceted structure, columned or spheroidal dendrites, and springy dendrites [28]. $\mathrm{Cu} 10, \mathrm{Cu} 10-8, \mathrm{Cu} 30$, and $\mathrm{Cu} 30-8$ are closely related to the faceted structure [Figure $4(\mathrm{a}, \mathrm{b}, \mathrm{d}, \mathrm{e})$ ], whereas $\mathrm{Cu}$ 10-14 and $\mathrm{Cu} 30-14$ are close to the springy dendrites [Figure 4(c, f)]

By an observation with the lower magnification, $\mathrm{Cu} 10-14$ shows a compact surface without a porous structure [Figure 4(c)], whereas $\mathrm{Cu} 30-14$ shows as a compact but porous surface. At the higher magnification, however, small nodules are recognized on both $\mathrm{Cu}$ 10-14 and $\mathrm{Cu}$ 30-14 samples. Such morphology is probably affected by a decrease in the amount of deposited copper on the substrate by increasing the magnetic field [29]. It is seen in $\mathrm{Cu} \mathrm{30-14}$. These

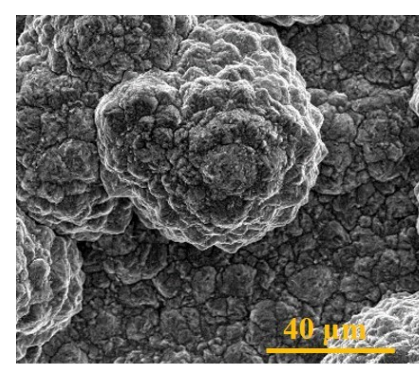

(a) $\mathrm{Cu} 10$

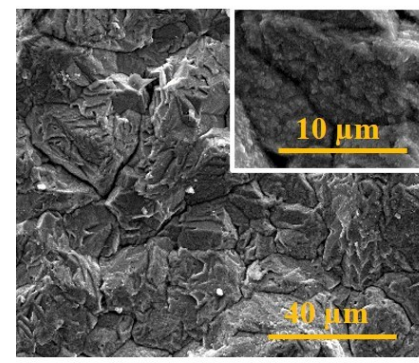

(c) $\mathrm{Cu} \mathrm{10-14}$

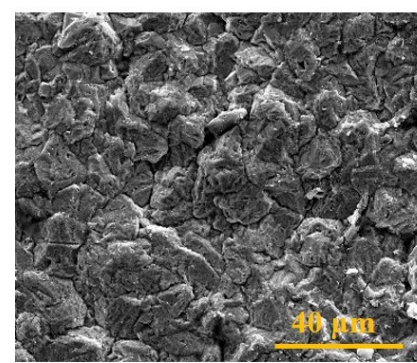

(e) $\mathrm{Cu} \mathrm{30-8}$

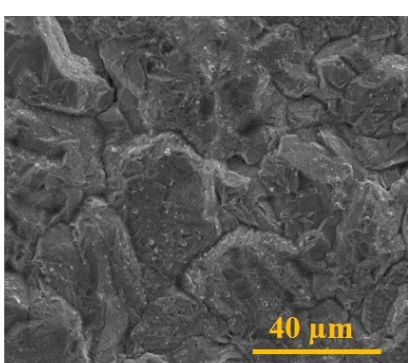

(b) $\mathrm{Cu} \mathrm{10-8}$

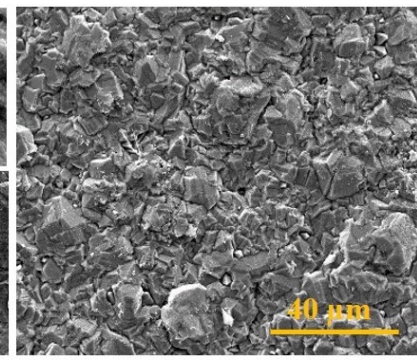

(d) $\mathrm{Cu} 30$

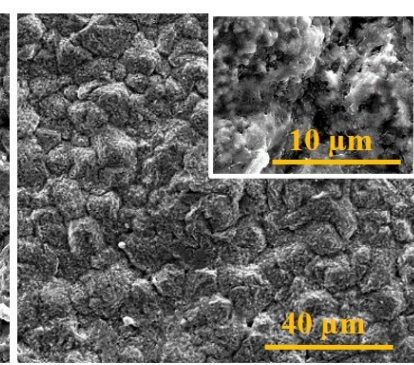

(f) $\mathrm{Cu} \mathrm{30-14}$
Figure 4: SEM images of electrodeposited $\mathrm{Cu}$ onto the $\mathrm{Al}$ alloy substrate with various current densities and magnetic fields: (a) $\mathrm{Cu}$ 10, (b) $\mathrm{Cu}$ 10-8, (c) $\mathrm{Cu}$ 10-14, (d) $\mathrm{Cu} 30$, (e) $\mathrm{Cu} 30-8$, and (f) $\mathrm{Cu}$ 30-14. phenomena are likely similar to the results reported by Fukukana et al. [28].

\section{Energy dispersive spectroscopy (EDS)}

EDS patterns of electrodeposited $\mathrm{Cu}$ onto the $\mathrm{Al}$ alloy substrate are presented in Figure 5. The EDS analysis of the $\mathrm{Cu}$ films shows only a significant peak of $\mathrm{Cu}$ and a slight peak of oxygen $(\mathrm{O})$ [30]. Other studies also found $\mathrm{Cu}$ and $\mathrm{O}$ before and after the treatment of the sample. The other research found the sulfur atoms on copper. This was caused by adsorption of inhibitors on the copper surface [31].

Based on Figure 5, the percentage of elements $\mathrm{Cu}$ and $\mathrm{O}_{2}$ was evaluated and is listed in Table 1. The magnetic field

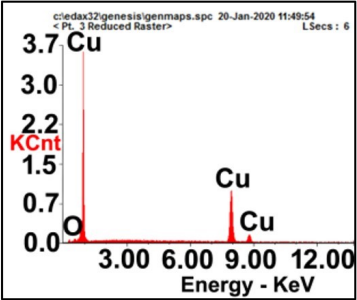

(a) $\mathrm{Cu} 10$

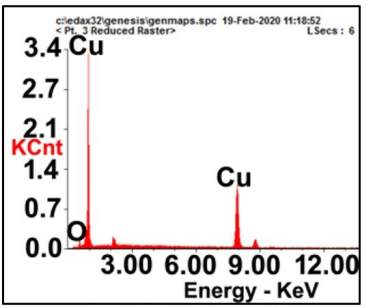

(c) $\mathrm{Cu} \mathrm{10-14}$

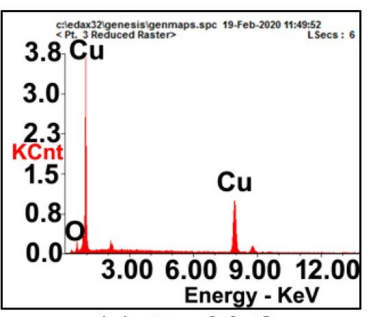

(e) $\mathrm{Cu} \mathrm{30-8}$

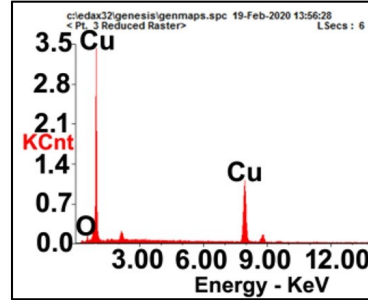

(b) $\mathrm{Cu} \mathrm{10-8}$

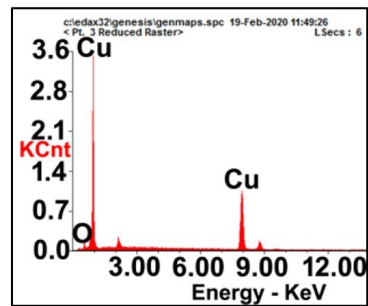

(d) $\mathrm{Cu} 30$

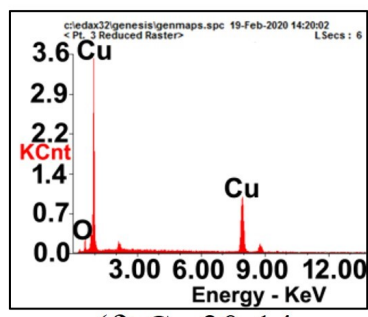

(f) $\mathrm{Cu} 30-14$
Figure 5: EDS of electrodeposited $\mathrm{Cu}$ onto the $\mathrm{Al}$ alloy substrate with various current densities and magnetic fields: (a) $\mathrm{Cu} 10$, (b) $\mathrm{Cu}$ 10-8, (c) Cu 10-14, (d) Cu 30, (e) Cu 30-8, and (f) $\mathrm{Cu} 30-14$.

Table 1: Oxygen and $\mathrm{Cu}$ contents on the electrodeposited $\mathrm{Cu}$ film with various current densities and magnetic fields.

\begin{tabular}{lcc}
\hline Sample & $\mathrm{O}_{2}(\mathrm{wt} \%)$ & $\mathrm{Cu}(\mathrm{wt} \%)$ \\
\hline $\mathrm{Cu} \mathrm{10}$ & 1.4 & 98.60 \\
$\mathrm{Cu} \mathrm{10-8}$ & 2.30 & 97.70 \\
$\mathrm{Cu} \mathrm{10-14}$ & 3.08 & 96.92 \\
$\mathrm{Cu} \mathrm{30}$ & 3.02 & 96.98 \\
$\mathrm{Cu} \mathrm{30-8}$ & 4.22 & 95.78 \\
$\mathrm{Cu} \mathrm{30-14}$ & 5.02 & 94.98 \\
\hline
\end{tabular}


and the current density affect the content of oxygen on the surface of the deposited copper film. Since the applied static magnetic field was perpendicular to the cathode surface, the Lorentz's force and the electrokinetic magneto-hydrodynamic were negligible. Therefore, the magnetic gradient force and the paramagnetic force are possible additional forces which affect the copper ions to be electrodeposited.

Molecular oxygen $\left(\mathrm{O}_{2}\right)$ is paramagnetic, and the magnet attracts the paramagnetic materials. During electrodeposition, $\mathrm{O}_{2}$ is also produced as a product of a secondary reaction at the anode. $\mathrm{O}_{2}$ can also diffuses from the air to the solution. The hydroxylation process is not possible, since the plating bath does not contain organic compounds and, from the EDS observation, carbon atoms are not detected. The magnetic field may attract $\mathrm{O}_{2}$ and, hence, the concentration of $\mathrm{O}_{2}$ on the surface increases as the magnetic field increases. $\mathrm{O}_{2}$ could form a copper oxide, but the oxide was not detected by XRD as shown below.

\section{X-ray diffractometry (XRD)}

The XRD patterns of the samples are presented in Figure 6. Rietveld refinement on the XRD pattern was conducted using the HighScore Plus software.

All the samples are polycrystalline, and the crystals have a face-centered cubic (FCC) structure, which shows three significant peaks for the (111), (002) and (022) planes. There is a single phase of copper and no other phase is present on the surfaces of the $\mathrm{Cu}$ films. The suspected $\mathrm{Cu}$ oxide is not detected from the XRD pattern, even though oxygen was detected from EDS spectra (Figure 5). This is probably due to a small amount of the oxide on the copper film surfaces.

The three significant peaks have different peak intensities, whereas the intensities of the (111) and (022) planes are more predominant than those of other peaks. The peaks intensities of all $h k l$ planes is listed in Table 2. The increase shows different electrochemical behavior. This is probably due to the different atomic surface density for each crystal plane.

To assess how the current density and the magnetic field affect crystal orientation, the orientation index, $M$, is calculated using the following equation [32], and the results are shown in Table 2.

$$
M(h k l)=\frac{I(h k l) / I_{0}(h k l)}{\frac{1}{n} \sum I\left(h^{\prime} k^{\prime} l^{\prime}\right) / I_{0}\left(h^{\prime} k^{\prime} l^{\prime}\right)}
$$

$M(h k l)$ is the calculated orientation index, $I(h k l)$ is the XRD peak intensity of each plane in the experimental data, $I_{0}(h k l)$ the peak intensity in the Inorganic Crystal Structure Database (ICSD), and $I\left(h^{\prime} k^{\prime} l^{\prime}\right)$ and $I_{0}\left(h^{\prime} k^{\prime} l^{\prime}\right)$ are the sums of three independent peak intensities of the experimental data and the ICSD data, respectively. The index value larger than $1[M(h k l) \geq 1]$ indicates that the $(h k l)$ plane is preferentially

(a) $10 \mathrm{~mA} \mathrm{~cm}^{-2}$

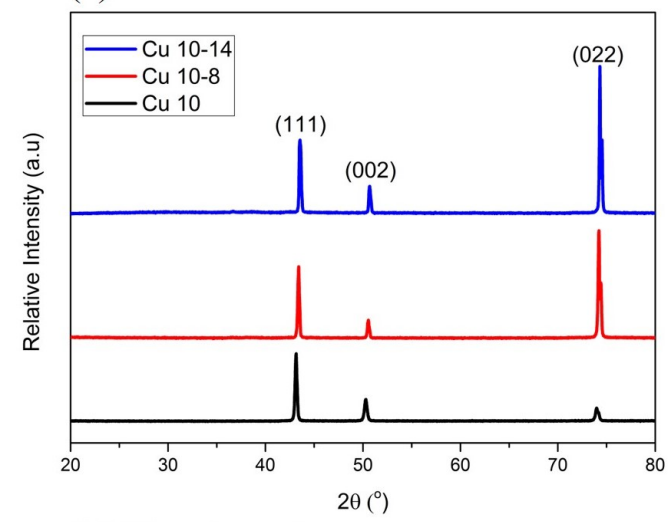

(b) $30 \mathrm{~mA} \mathrm{~cm}^{-2}$

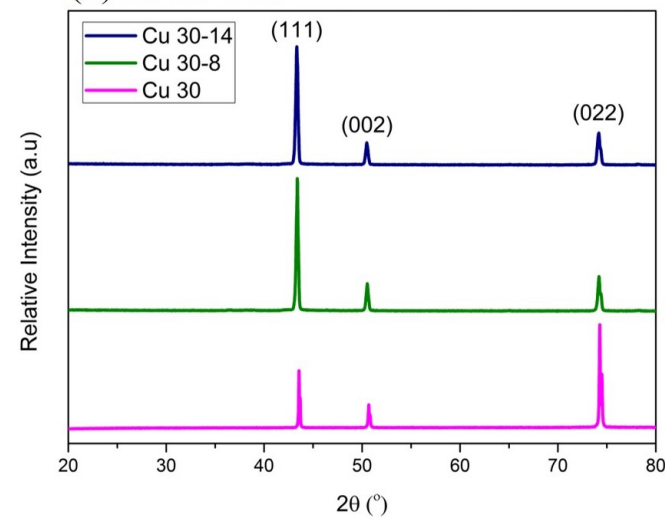

Figure 6: XRD patterns of electrodeposited $\mathrm{Cu}$ onto the $\mathrm{Al}$ alloy substrate with varies current densities and magnetic fields: (a) 10 $\mathrm{mA} \mathrm{cm}{ }^{-2}$ and (b) $30 \mathrm{~mA} \mathrm{~cm}^{-2}$ with and without magnetic fields.

Table 2: Peaks intensities of various $h k l$ and the orientation index, $M(h k l)$, for electrodeposited $\mathrm{Cu}$ onto the $\mathrm{Al}$ alloy substrate with different current densities and magnetic fields.

\begin{tabular}{|c|c|c|c|c|c|c|}
\hline \multirow{2}{*}{ Sample } & \multicolumn{3}{|c|}{$h k l$ (a.u.) } & \multicolumn{3}{|c|}{$M(h k l)$} \\
\hline & 111 & 002 & 022 & 111 & 002 & 022 \\
\hline $\mathrm{Cu} 10$ & 8904 & 3060 & 1944 & 1.098 & 0.809 & 1.092 \\
\hline $\mathrm{Cu} 10-8$ & 9883 & 3068 & 14485 & 0.321 & 0.190 & 2.486 \\
\hline $\mathrm{Cu} 10-14$ & 10246 & 4345 & 19652 & 0.286 & 0.185 & 2.528 \\
\hline $\mathrm{Cu} 30$ & 12221 & 5320 & 21516 & 0.314 & 0.180 & 2.505 \\
\hline $\mathrm{Cu} 30-8$ & 27612 & 6362 & 7791 & 1.014 & 0.548 & 1.438 \\
\hline $\mathrm{Cu} 30-14$ & 24730 & 5302 & 7276 & 1.054 & 0.779 & 1.383 \\
\hline
\end{tabular}


grown, while the index smaller than $1[M(h k l)<1]$ means that the growth of the $(h k l)$ plane is suppressed.

At $10 \mathrm{~mA} \mathrm{~cm}^{-2}$, the magnetic field affects the growth of the (022) plane. The peak height of the (022) plane increases faster than those of two other peaks of the (111) and (002) planes. At $30 \mathrm{~mA} \mathrm{~cm}^{-2}$, increasing the magnetic field results in suppression of the (022) plane and an enhanced growth of the (111) plane. The (111) peak surpasses the other two peaks. This alteration of the peak orientation is due to the magnetic field. The (111) plane has a higher surface atomic density than the two other planes.

The magnetic field affects the growth of certain planes in a sufficient field strength. The crystal plane with a higher surface atomic density has the first probability to be created or deposited. This is due to attraction of $\mathrm{Cu}^{2+}$ to the magnet. Hence, the concentration of $\mathrm{Cu}^{2+}$ on the proximity of the surface becomes greater. Preferred orientation to the (111) plane for copper offers additional benefits such as better corrosion resistance, increase electrical conductivity, and improve mechanical properties [33].

Table 3 presents the crystal parameters of the samples after Rietveld refinement by using the HighScore Plus software. Rietveld refinement was conducted until the good of fitness of less than $2.5 \%$ and $R$-weighted pattern of less than $10 \%$. The crystallite size was determined by measuring a full width at half of its maximum intensity (FWHM) (rad) [34]. The FWHM of the peak $\left(\beta_{0}\right)$ is composed of both instrumental FWHM $\left(\beta_{\mathrm{i}}\right)$ and the FWHM of the sample $(\beta)$. $\beta$ is calculated by the Warren-Averbach equation [35]; $\beta^{2}=$ $\beta_{0}^{2}-\beta_{\mathrm{i}}^{2}$, where, $\beta_{\mathrm{i}}$ was calculated from the FWHM of silicon as a standard material. In this study, the WilliamsonHall equation was taken to estimate the crystallite size of the samples [36].

$$
\beta \cos \theta=\frac{0.9 \lambda}{D}+\varepsilon \sin \theta
$$

Here, $D$ is the average crystallite size, $\varepsilon$ is an internal microstrain, $\lambda$ is the wavelength and equals $0.1541 \mathrm{~nm}$, and $\theta$ is the Bragg angle of the X-ray diffraction. By plotting the Williamson-Hall equation with the $y$-axis being $\beta \cos \theta$ and the $x$-axis being $\sin \theta, D$ is obtained from the cross point and $\varepsilon$ is determined from the slope of the plotted line. The positive slope indicates a tensile residual stress, while the negative slope suggests a compressive residual stress. It is found that the crystallite size is less than $100 \mathrm{~nm}$. The internal strain is positive for the sample with the current density of $10 \mathrm{~mA} \mathrm{~cm}$. An atomic position and the site occupancy were also refined, and they are not changed.

\section{E. Linear sweep voltammetry (LSV)}

LSV is one of voltammetry methods in which the current at the working electrode is measured while the potential between the working electrode and the reference electrode is swept linearly over time. The curve of LSV is composed of two parts; an anodic part resulting from the anodic dissolution of $\mathrm{Cu}$ and a cathodic part corresponding to the cathodic reaction which is an oxygen reduction reaction in the present case.

The LSV curves of electrodeposited $\mathrm{Cu}$ onto the $\mathrm{Al}$ alloy substrates are presented in Figure 7. It can be seen that the anodic parts of the polarization curves for all $\mathrm{Cu}$ samples which were formed with and without the magnetic field are a little bit different. Before copper metal dissolution, the anodic part of the LSV curve is related to $\mathrm{CuCl}^{-}$which adsorbs on the film surface. Due to $\mathrm{Cu}$ dissolution, the current density rises with a rise of the potential by a direct formation of $\mathrm{CuCl}$ [Eq. (1)] or by $\mathrm{Cu}^{+}$dissolution to form $\mathrm{CuCl}$ [Eqs. (2) and (3)] [25].

$$
\begin{aligned}
& \mathrm{Cu}+\mathrm{Cl}^{-} \rightarrow \mathrm{CuCl}+\mathrm{e}^{-} \\
& \mathrm{Cu} \rightarrow \mathrm{Cu}^{+}+\mathrm{e}^{-} \\
& \mathrm{Cu}^{+}+\mathrm{Cl}^{-} \rightarrow \mathrm{CuCl}
\end{aligned}
$$

Formation of $\mathrm{CuCl}_{2}^{-}$is observed at a greater concentration

\begin{tabular}{|c|c|c|c|c|c|c|c|}
\hline & & $\mathrm{Cu} 10$ & $\mathrm{Cu} 10-8$ & $\mathrm{Cu} \mathrm{10-14}$ & $\mathrm{Cu} 30$ & $\mathrm{Cu} 30-8$ & $\mathrm{Cu} 30-14$ \\
\hline Lattice constant $(\AA)$ & & 3.6113 & 3.6135 & 3.6168 & 3.6237 & 3.6144 & 3.6147 \\
\hline Volume $\left(\AA^{3}\right)$ & & 47.09 & 47.18 & 47.31 & 47.59 & 47.21 & 47.23 \\
\hline Crystal system & & Cubic & Cubic & Cubic & Cubic & Cubic & Cubic \\
\hline Crystallite size (nm) & & 41 & 60 & 52 & 69 & 18 & 36 \\
\hline Strain & & 0.0004 & 0.0007 & 0.0017 & -0.0011 & -0.0127 & 0.0011 \\
\hline \multirow{4}{*}{ Atomic position } & $x$ & 0 & 0 & 0 & 0 & 0 & 0 \\
\hline & $y$ & 0 & 0 & 0 & 0 & 0 & 0 \\
\hline & $z$ & 0 & 0 & 0 & 0 & 0 & 0 \\
\hline & Occupancy & 1 & 1 & 1 & 1 & 1 & 1 \\
\hline$R$-weighted pattern & & 8 & 5.37 & 6.02 & 8.84 & 7.61 & 7.2 \\
\hline Goodness of fit & & 1.05 & 1 & 1.48 & 2.42 & 2.35 & 2.11 \\
\hline
\end{tabular}
of chloride; $\mathrm{CuCl}+\mathrm{Cl}^{-} \rightarrow \mathrm{CuCl}_{2}^{-}$. Corrosion of $\mathrm{Cu}$ in the chloride environments takes place through the cathodic

Table 3: Crystal parameters of the $\mathrm{Cu}$ films at the current densities of 10 and $30 \mathrm{~mA} \mathrm{~cm}^{-2}$ with the magnetic fields of 0,800 , and $1400 \mathrm{G}$. 

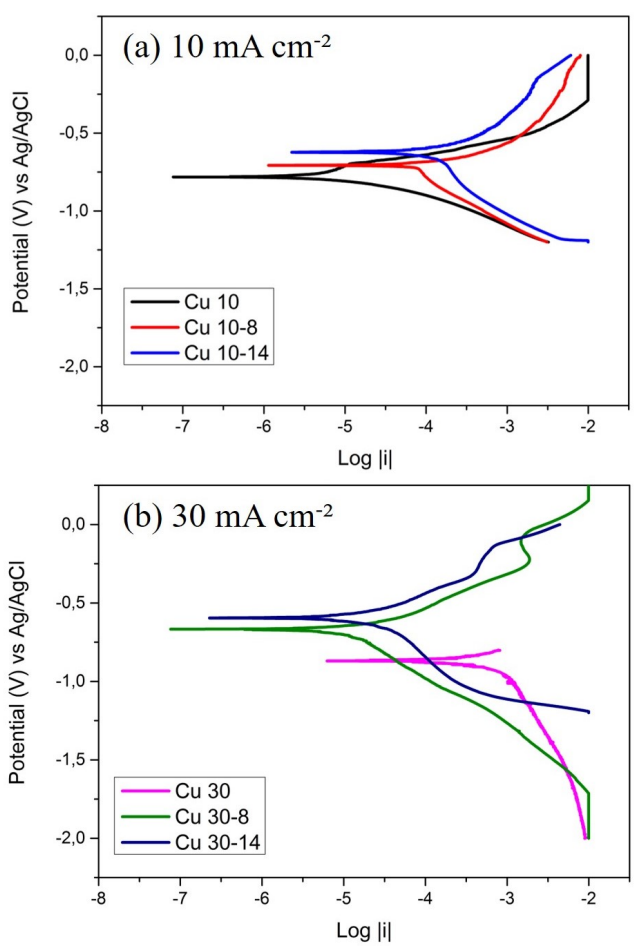

Figure 7: LSV measurements of electrodeposited $\mathrm{Cu}$ on the $\mathrm{Al}$ alloy substrate with various current densities and magnetic fields: (a) $10 \mathrm{~mA} \mathrm{~cm}^{-2}$ and (b) $30 \mathrm{~mA} \mathrm{~cm}^{-2}$ with and without the magnetic field.

reaction, $\mathrm{O}_{2}+2 \mathrm{H}_{2} \mathrm{O}+4 \mathrm{e}^{-} \rightarrow 4 \mathrm{OH}^{-}$, and the anodic reactions as shown in Eqs. (1) and (2) [25].

Figure 7(a) shows that, for $10 \mathrm{~mA} \mathrm{~cm} \mathrm{~cm}^{-2}$, the corrosion potential $\left(E_{\text {corr }}\right)$ shifts to a more positive side in the stronger magnetic field. A similar phenomenon is also found for the sample with the current density of $30 \mathrm{~mA} \mathrm{~cm}^{-2}$ [Figure 7(b)] Elias et al. found in the Ni-W coating [5] that the perpendicular magnetic field resulted in the shift of $E_{\text {corr }}$ to a more positive side. To evaluate a corrosion resistance, $E_{\text {corr }}$ and a corrosion current density $\left(i_{\text {corr }}\right)$ were determined by the Tafel extrapolation. The corrosion resistance is defined by the following equation [37].

$$
C r=C \frac{M i_{\text {corr }}}{n \rho}
$$

$\mathrm{Cr}$ is the corrosion rate (mmpy; mm years ${ }^{-1}$ ), $C$ is a constant for the corrosion rate calculation and is $3.27 \mathrm{mmpy}$ [38], $M$ is the atomic weight $\left(\mathrm{g} \mathrm{mol}^{-1}\right), i_{\text {corr }}$ is corrosion current density $\left(\mathrm{A} \mathrm{cm}^{-1}\right), n$ is the number of electrons involve, and $\rho$ is the density of $\mathrm{Cu}\left(\mathrm{g} \mathrm{cm}^{-3}\right)$. The summary of the calculation for the corrosion rates is tabulated in Table 4.

As the magnetic field increases, $E_{\text {corr }}$ shifts to a higher potential. This is probably due to the increased oxygen content on the sample surface to form an oxide with copper. As the current density increases from 10 to $30 \mathrm{~mA} \mathrm{~cm}$, $E_{\text {corr }}$ shifts to the lower potential. The change of $i_{\text {corr }}$ does not seem to depend only on the magnetic field, but other factors could also contribute. The corrosion rate of the FCC
Table 4: LSV measurements of electrodeposited $\mathrm{Cu}$ on the $\mathrm{Al}$ alloy substrate with various current densities and magnetic fields.

\begin{tabular}{lccc}
\hline Sample & $i_{\text {corr }}\left(\mathrm{A} \mathrm{cm}^{-2}\right)$ & $E_{\text {corr }}(\mathrm{V})^{a}$ & $C r(\mathrm{mmpy})$ \\
\hline $\mathrm{Cu} \mathrm{10}$ & $6.57 \times 10^{-6}$ & -0.781 & 0.0716 \\
$\mathrm{Cu} \mathrm{10-8}$ & $1.36 \times 10^{-4}$ & -0.707 & 1.48 \\
$\mathrm{Cu} \mathrm{10-14}$ & $1.05 \times 10^{-4}$ & -0.623 & 1.14 \\
$\mathrm{Cu} \mathrm{30}$ & $2.70 \times 10^{-4}$ & -0.870 & 2.94 \\
$\mathrm{Cu} \mathrm{30-8}$ & $9.08 \times 10^{-6}$ & -0.668 & 0.0989 \\
$\mathrm{Cu} \mathrm{30-14}$ & $1.37 \times 10^{-5}$ & -0.596 & 0.149 \\
\hline
\end{tabular}

${ }^{a}$ Values with respect to the $\mathrm{Ag} / \mathrm{AgCl}$ reference electrode.

materials depends on orientation of the crystallographic plane on the sample surface. The (111) plane of the FCC materials, which has the highest surface atomic density, is more resistant to corrosion than the (002) and (022) planes. The crystallite size, the strain, and other defects could also influence the corrosion rate. Al Kharafi et al. have found that $\mathrm{Cu}$ in the $3.5 \% \mathrm{NaCl}$ solution has a corrosion potential $E_{\text {corr }}=-0.187 \mathrm{~V}$ (vs. $\mathrm{Ag} / \mathrm{AgCl}$ ) [39]. The corrosion potential of the $\mathrm{Cu}$ films in the present study is less negative than that reported by Al Kharafi et al.

\section{F. Water contact angle}

The water contact angles (wettability) on the electrodeposited $\mathrm{Cu}$ films onto the $\mathrm{Al}$ alloy substrate are presented in Figure 8. The oxygen content on the surface increases as the magnetic field and the current density increase. Oxygen and copper form an oxide, and more oxide are formed on the surface as the magnetic field becomes stronger. An increase in the contact angle with the magnetic field means that the surface becomes more hydrophobic. Water is a polar

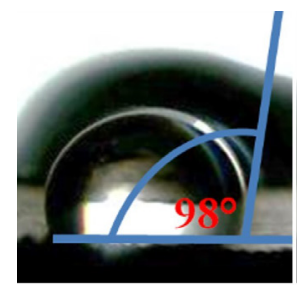

(a) $\mathrm{Cu} 10$

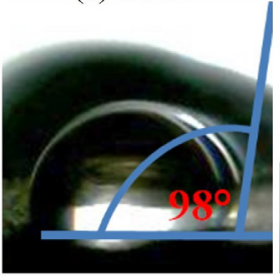

(d) $\mathrm{Cu} 30$

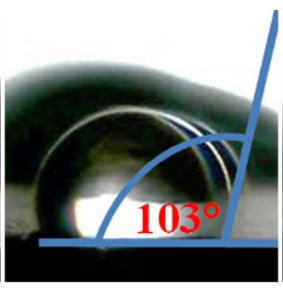

(b) $\mathrm{Cu} 10-8$

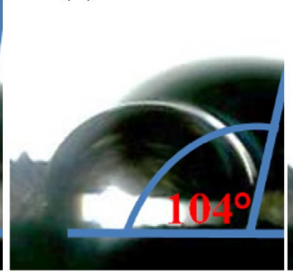

(e) $\mathrm{Cu} 30-8$

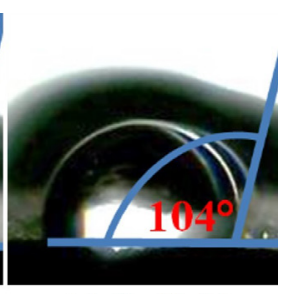

(c) $\mathrm{Cu} 10-14$

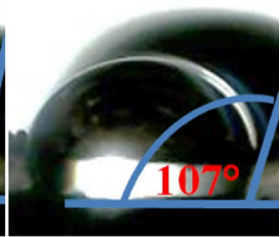

(f) $\mathrm{Cu} 30-14$
Figure 8: Water contact angle measurements of electrodeposited $\mathrm{Cu}$ on the $\mathrm{Al}$ alloy substrate with various current densities and magnetic fields: (a) $\mathrm{Cu} 10$, (b) $\mathrm{Cu} \mathrm{10-8,} \mathrm{(c)} \mathrm{Cu} 10-14$, (d) $\mathrm{Cu} 30$, (e) $\mathrm{Cu} 30-8$ and (f) $\mathrm{Cu} 30-14$. 
molecule, whereas the copper oxide is not a polar molecule. Therefore, the contact angle increases as the magnetic field and the current density increase. The contact angle of all samples is more than $90^{\circ}$. Namely, all samples meet the hydrophobic criteria, $150^{\circ}>\theta \geq 90^{\circ}[40]$

\section{CONCLUSION}

Presence of the magnetic field during electrodeposition of $\mathrm{Cu}$ on the $\mathrm{Al}$ alloy with various current densities affects the cathode current efficiency, the deposition rate, surface morphology, the oxygen content, crystallographic plane orientation, the corrosion potential, the corrosion rate, and wettability. The oxygen content on the surface of the $\mathrm{Cu}$ film increases as the magnetic field and the current density increase. It is not doubted that the magnetic field can be used to control the properties needed of the $\mathrm{Cu}$ film for a certain application.

\section{Acknowledgments}

The author thanks Ministry of Research, Technology and Higher Education of the Republic of Indonesia for financial support Hibah Penelitian Disertasi Doktor No: NKB-2999/UN2.RST/HKP.05.00 12020

\section{References}

[1] Z. Wang, Y. Zhang, and R. Yang, J. Manuf. Process. 15, 34 (2013).

[2] C. Gabrielli, P. Moçotéguy, H. Perrot, and R. Wiart, J. Electroanal. Chem. 572, 367 (2004).

[3] X. Yi and Q. Yang, e-J. Surf. Sci. Nanotechnol. 16, 310 (2018).

[4] F. B. Susetyo, M. C. Fajrah, and B. Soegijono, e-J. Surf. Sci. Nanotechnol. 18, 223 (2020).

[5] L. Elias and A. C. Hegde, J. Alloys Compd. 712, 618 (2017).

[6] L. Wen, Y. Wang, Y. Jin, B. Liu, Y. Zhou, and D. Sun, Surf. Coat. Technol. 228, 92 (2013).

[7] T. Wang and W. Chen, ECS Electrochem. Lett. 4, D14 (2015).

[8] C. Wang, Y.-B. Zhong, J. Wang, Z.-q. Wang, W.-L. Ren, Z.-S. Lei, and Z.-M. Ren, J. Electroanal. Chem. 630, 42 (2009).

[9] K. Nishikawa, T. Saito, H. Matsushima, and M. Ueda, Electrochim. Acta 297, 1104 (2019).

[10] M. Zieliński, Mater. Chem. Phys. 141, 370 (2013).

[11] F. M. F. Rhen, G. Hinds, and J. M. D. Coey, Electrochem. Commun. 6, 413 (2004).

[12] F. M. F. Rhen, D. Fernandez, G. Hinds, and J. M. D. Coey, J. Electrochem. Soc. 153, J1 (2006).

[13] F. B. Susetyo, E. M. H. Situmorang, S. Luthfiya, and B. Soegijono, MATEC Web Conf. 218, 04026 (2018).

[14] H. A. Murdoch, D. Yin, E. Hernández-Rivera, and A. K. Giri, Electrochem. Commun. 97, 11 (2018).

[15] B.-N. Park, Y.-S. Sohn, and S.-Y. Choi, Microelectron. Eng. 85, 308 (2008).

[16] C. O'Reilly, G. Hinds, and J. M. D. Coey, J. Electrochem. Soc. 148, C674 (2001).

[17] T. Z. Fahidy, J. Appl. Electrochem. 13, 553 (1983).
[18] R. N. O’Brien and K. S. V. Santhanam, J. Appl. Electrochem. 27, 573 (1997).

[19] C.-C. Hung, W.-H. Lee, S.-C. Chang, G.-J. Hwang, and Y.-L. Wang, Jpn. J. Appl. Phys. 48, 076506 (2009).

[20] S. R. Ragsdale, K. M. Grant, and H. S. White, J. Am. Chem. Soc. 120, 13461 (1998).

[21] Y. Tanimoto, H. Yano, S. Watanabe, A. Katsuki, W. Duan, and M. Fujiwara, Bull. Chem. Soc. Jpn. 73, 867 (2000).

[22] N. D. Nikolić and K. I. Popov, in: Electrodeposition: Theory and Practice, edited by S. S. Djokic (Springer, NewYork, 2010) pp. $1-70$.

[23] J. R. Davis (Ed.), ASM Specialty Handbook: Nickel, Cobalt, and Their Alloys (ASM International, Materials Park, Ohio, 2000).

[24] R. Sekar, Trans. Nonferrous Met. Soc. China 27, 1665 (2017).

[25] C. R. Thurber, Y. H. Ahmad, S. F. Sanders, A. Al-Shenawa, N. D’Souza, A. M. A. Mohamed, and T. D. Golden, Curr. Appl. Phys. 16, 387 (2016).

[26] T. Z. Fahidy, Prog. Surf. Sci. 68, 155 (2001).

[27] H. Matsushima, A. Bund, W. Plieth, S. Kikuchi, and Y. Fukunaka, Electrochim. Acta 53, 161 (2007).

[28] Y. Fukunaka, H. Doi, and Y. Kondo, J. Electrochem. Soc. 137, 88 (1990)

[29] D. Fernández and J. M. D. Coey, Electrochem. Commun. 11, 379 (2009).

[30] Z. Z. Tasic, M. M. Antonijevic, M. B. Petrovic Mihajlovic, and M. B. Radovanovic, J. Mol. Liq. 219, 463 (2016).

[31] M. B. Radovanović and M. M. Antonijević, J. Adhes. Sci. Technol. 31, 369 (2016).

[32] C. S. Barrett and T. B. Massalski, Structure of Metals: Crystallographic Methods, Principles, and Data, 3rd ed. (McGraw-Hill, New York, 1966).

[33] R. Seakr, Trans. Nonferrous Met. Soc. China 27, 1423 (2017).

[34] C. K. Chung, W. T. Chang, C. F. Chen, and M. W. Liao, Mater. Lett. 65, 416 (2011).

[35] J. Ghosh, S. K. Chattopadhayay, A. K. Meikap, and S. K. Chatterjee, J. Alloys Compd. 453, 131 (2008).

[36] G. K. Williamson and W. H. Hall, Acta Metall. 1, 22 (1953).

[37] Z. Yang, X. Liu, and Y. Tian, Colloids Surf. A 560, 205 (2019).

[38] Z. Ahmad, Principles of Corrosion Engineering and Corrosion Control (Butterworth-Heinemann, Oxford, 2006) Chap. 3.

[39] F. M. Al Kharafi, I. M. Ghayad, and R. M. Adallah, e-J. Surf. Sci. Nanotechnol. 9, 306 (2011).

[40] Y. Shen, X. Wu, J. Tao, C. Zhu, Y. Lai, and Z. Chen, Prog. Mater. Sci. 103, 509 (2019).

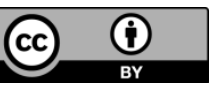

All articles published on e-J. Surf. Sci. Nanotechnol. are licensed under the Creative Commons Attribution 4.0 International (CC BY 4.0). You are free to copy and redistribute articles in any medium or format and also free to remix, transform, and build upon articles for any purpose (including a commercial use) as long as you give appropriate credit to the original source and provide a link to the Creative Commons (CC) license. If you modify the material, you must indicate changes in a proper way.

Published by The Japan Society of Vacuum and Surface Science 